\title{
DO MEN WHO HAVE SEX WITH MEN USE SEROSORTING WITH CASUAL PARTNERS IN FRANCE? RESULTS OF A NATIONWIDE SURVEY (ANRS-EN17-PRESSE GAY 2004)
}

\author{
A Velter (a.velter@invs.sante.fr) ${ }^{1}$, A Bouyssou-Michel ${ }^{1}$, A Arnaud $^{1}$, C Semaille $^{1}$ \\ 1. Unité VIH/sida-IST-VHC-VHB chronique (HIV, AIDS, STI, HCV, chronic HBV unit), Département des maladies infectieuses \\ (Department of infectious diseases), Institut de veille sanitaire (French Institute for Public Health Surveillance), \\ Saint-Maurice, France
}

This article was published on 26 November 2009.

Citation style for this article: Velter A, Bouyssou-Michel A, Arnaud A, Semaille C. Do men who have sex with men use serosorting with casual partners in France? Results of a nationwide survey (ANRS-EN17-Presse Gay 2004). Euro Surveill. 2009;14(47):pii=19416. Available online: http://www.eurosurveillance.org/ViewArticle.aspx?ArticleId=19416

We examined whether men who have sex with men (MSM) in France have adopted serosorting with their casual partners, serosorting being one strategy to reduce the risk of HIV transmission. We expected to see the same predictors of this practice with casual partners in France as in other similar MSM communities (HIVseropositive, Internet dating). Data from a cross-sectional survey was used, based on a self-administered questionnaire conducted among readers of the gay press and users of gay websites in 2004. The study population consisted of MSM who reported their HIV status, as well as the practice of unprotected anal intercourse (UAI) with a casual partner at least once during the previous 12 months. Among 881 respondents included in the analysis, 195 (22\%) had practiced serosorting: 14\% among HIV-seropositive men and $26 \%$ among HIV-seronegative men. Serosorting was independently associated with the use of cruising venues (AOR $0.28, p=0.001)$ and Internet dating (AOR 2.16, p=0.051) among HIV-seropositive men, whereas it was independently associated with the use of cruising venues (AOR 0.59, $p=0.013$ ) and the fact of having less partners (AOR 1.50, p=0.046) among HIVseronegative men. Serosorting requires an up-to-date knowledge of HIV serostatus for MSM and their UAI casual partners, and does not prevent from acquiring other sexually transmitted infections. Prevention campaigns are needed to underline the risks associated with serosorting.

\section{Introduction}

Since 2003, an increase in new HIV diagnoses among men who have sex with men (MSM) has been observed by the mandatory notification system for HIV infection in France [1] as well as in many European countries [2]. During the same period, it was reported that half of MSM diagnosed with syphilis were also HIVseropositive [3]. More recently, cases of rectal lymphogranuloma venereum (LGV) have been diagnosed exclusively among MSM, most of whom were HIV-seropositive [3]. In 2000, for the first time since its inception in 1985, the French Gay Press Survey (EPG) showed an increase in sexual risk behaviours among MSM [4]. This trend was confirmed by the results of the latest EPG survey, conducted in 2004 , in which $33 \%$ of respondents reported unprotected anal intercourse (UAI) with casual partners [5] . Among men who had at least one casual partner, UAI was reported by $56 \%$ of HIV-positive respondents and $28 \%$ of HIV-negative respondents
[5]. Similar patterns have been documented since 1996 in the United States [6], Australia [7] and, slightly later, in Europe [8,9].

Recently, sexual behaviours aiming at reducing the risk of HIV transmission have been reported: serosorting with casual partners, negotiated safety with regular partners, strategic positioning, withdrawal before ejaculation [10-13]. The first, serosorting, consists of engaging in unprotected anal sex only with partners of the same HIV serostatus as oneself. This strategy has been described as being used by MSM in several cities in industrialised countries [14-17]. It is mainly employed by HIV-seropositive MSM who use the Internet to find sexual partners $[14,16,18]$. Osmond et al. showed that this strategy was used most frequently by the 18-29-year-olds [17]. This practice has also been described among HIV-negative men [11,19-22]. To date, serosorting with casual partners has never been studied in France.

The aim of this study was to determine whether MSM who did not use condoms for anal sex with casual partners adopted the strategy of serosorting, and to describe the men thus identified. We expected to see the same predictors of this practice with casual partners in France as in other similar MSM communities worldwide (HIV-seropositive, Internet dating). The study was based on our nationwide gay press and gay website survey carried out in late 2004.

\section{Methods}

\section{Survey}

The French Gay Press Survey (EPG) was first conducted in 1985. It was repeated each year until 1993, and subsequently every three or four years. The recruitment protocol has been unchanged since 1985. It consists in placing a questionnaire inside gay magazines with large readerships, and inviting readers to complete it on a voluntary basis. Questionnaires are returned to the French Institute for Public Health Surveillance (Institut de veille sanitaire, InVS). During the last survey in 2004, for the first time, the questionnaire was also posted on gay websites. The magazines and websites could be of a general or pornographic, national or regional character. Sixteen gay magazines and ten gay websites made available the questionnaire between July and October 2004, and responses were collected until February 2005. 
The self-administered questionnaire comprised 100 wideranging questions on the respondent's sociodemographic characteristics, social and sexual life, sexual practices, history of sexually transmitted infection (STI), and self-reported HIV serostatus. Specifically, some questions addressed the respondent's sexual behaviour in the previous 12 months, including the number of male sexual partners, the type of sexual practices (e.g. anal sex), and the number of UAI; further questions focussed on the respondent's sexual risk behaviours, if any, with regular or casual partners. Respondents who had had at least one casual partner during the previous 12 months were asked about their sexual practices with those casual partner(s), and their knowledge of the HIV serostatus of UAI partners.

For 20 years, this survey has aimed at monitoring preventive sexual behaviours, lifestyles and sociability among MSM. The EPG survey constitutes one part of the French sexual behavioural MSM surveillance program; some questions are kept similar in each

\section{F I G U R E}

Number of respondents meeting the inclusion criteria for the analysis of serosorting, France (ANRS-EN17-Presse Gay 2004)

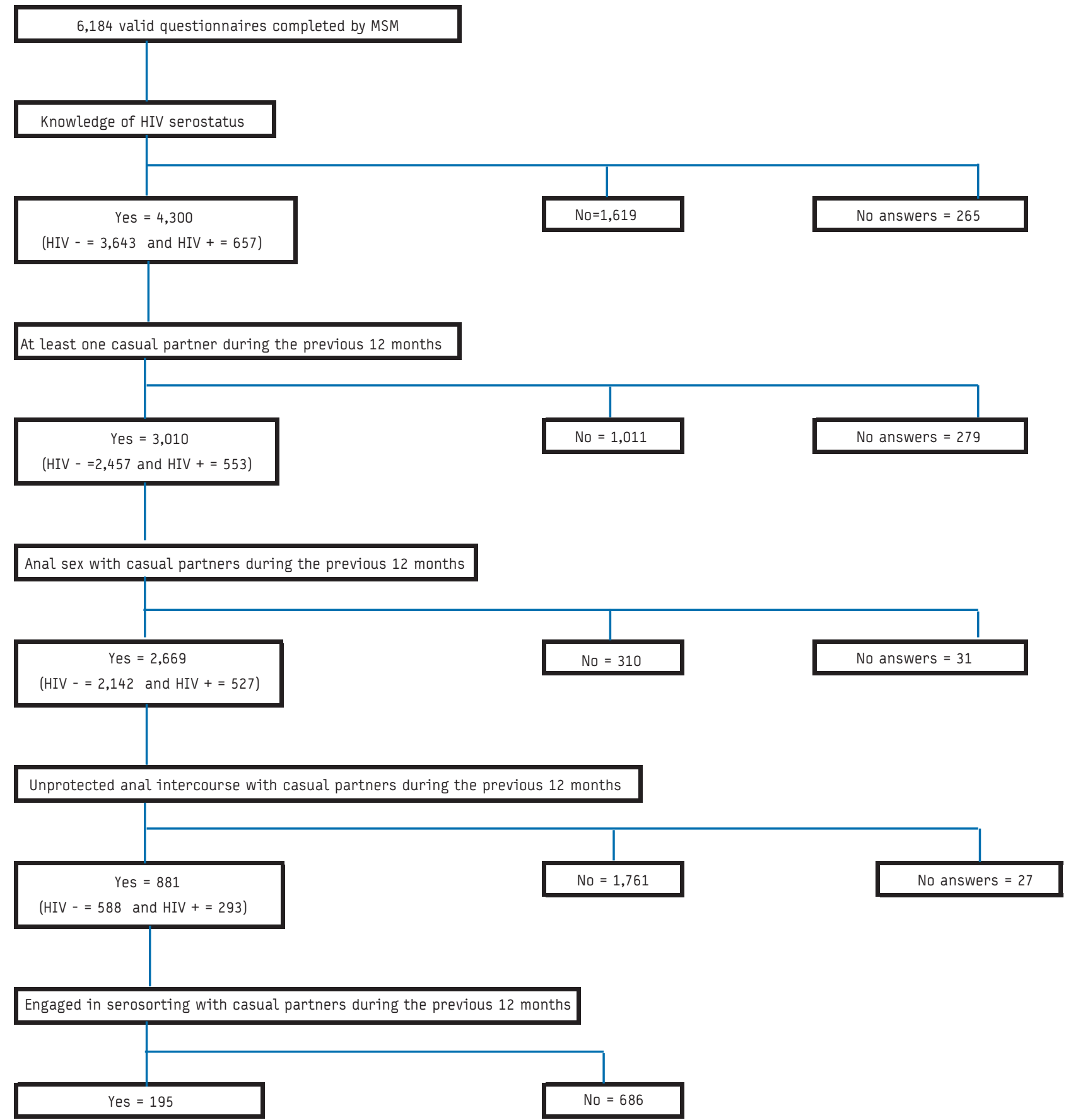


TA B L E 1

Sociodemographic characteristics, sexual practices and HIV testing history of respondents who had unprotected anal intercourse with a casual partner at least once in the previous 12 months, according to the use of serosorting, France (ANRS

EN17-Presse Gay 2004)

\begin{tabular}{|c|c|c|c|c|c|}
\hline & \multicolumn{4}{|c|}{ Serosorting } & \\
\hline & \multicolumn{2}{|c|}{ Yes } & \multicolumn{2}{|c|}{ No } & \\
\hline & $\mathrm{N}$ & $\%$ & $\mathrm{n}$ & $\%$ & \\
\hline & 195 & 22.1 & 686 & 77.9 & \\
\hline Categorical variables & $\mathrm{N}$ & $\%$ & $n$ & $\%$ & $p$ \\
\hline \multicolumn{6}{|l|}{ Type of questionnaires } \\
\hline Pen and paper questionnaires & 139 & 71.3 & 494 & 72.0 & 0.842 \\
\hline Online questionnaires & 56 & 28.7 & 192 & 28.0 & \\
\hline \multicolumn{6}{|l|}{ Education } \\
\hline High school or lower & 77 & 39.9 & 261 & 38.3 & 0.682 \\
\hline University & 116 & 60.1 & 421 & 61.7 & \\
\hline \multicolumn{6}{|l|}{ Residence } \\
\hline Paris region & 80 & 46.0 & 254 & 41.2 & 0.257 \\
\hline Other regions of France & 94 & 54.0 & 363 & 58.8 & \\
\hline \multicolumn{6}{|l|}{ Living } \\
\hline Alone & 108 & 56.0 & 375 & 54.9 & 0.893 \\
\hline With a man (couple) & 56 & 29.0 & 210 & 30.8 & \\
\hline Other & 29 & 15.0 & 98 & 14.3 & \\
\hline \multicolumn{6}{|l|}{ Sexual orientation } \\
\hline Gay / homosexual & 172 & 89.6 & 609 & 89.6 & 0.992 \\
\hline Other & 20 & 10.4 & 71 & 10.4 & \\
\hline \multicolumn{6}{|l|}{ Looking for sexual partners in backrooms } \\
\hline Yes & 72 & 37.7 & 320 & 47.1 & 0.022 \\
\hline No & 119 & 62.3 & 360 & 52.9 & \\
\hline \multicolumn{6}{|l|}{ Looking for sexual partners in saunas } \\
\hline Yes & 70 & 36.6 & 330 & 48.5 & 0.004 \\
\hline No & 121 & 63.4 & 350 & 51.5 & \\
\hline \multicolumn{6}{|l|}{ Looking for sexual partners in cruising venues } \\
\hline Yes & 58 & 30.4 & 343 & 50.4 & $<0.001$ \\
\hline No & 133 & 69.6 & 337 & 49.6 & \\
\hline \multicolumn{6}{|l|}{ Looking for sexual partners on websites } \\
\hline Yes & 111 & 58.1 & 347 & 51.0 & 0.083 \\
\hline No & 80 & 41.9 & 333 & 49.0 & \\
\hline \multicolumn{6}{|c|}{ Drinking over five glasses of alcohol, on consumption days } \\
\hline Yes & 30 & 18.4 & 119 & 21.2 & 0.435 \\
\hline No & 133 & 81.6 & 442 & 78.8 & \\
\hline \multicolumn{6}{|l|}{ Drug use (at least one product except cannabis) } \\
\hline Yes & 46 & 24.1 & 214 & 31.4 & 0.051 \\
\hline No & 145 & 75.9 & 468 & 68.6 & \\
\hline \multicolumn{6}{|l|}{ Oral sex with casual partners (previous 12 months) } \\
\hline No oral sex & 1 & 0.6 & 2 & 0.3 & 0.969 \\
\hline Always protected oral sex & 5 & 2.8 & 19 & 3.0 & \\
\hline No sperm exposure during unprotected oral sex & 58 & 32.4 & 209 & 32.6 & \\
\hline Sperm exposure during oral sex & 115 & 64.2 & 411 & 64.1 & \\
\hline \multicolumn{6}{|l|}{ At least one STI (previous 12 months) } \\
\hline Yes & 33 & 17.0 & 155 & 22.8 & 0.085 \\
\hline No & 161 & 83.0 & 526 & 77.2 & \\
\hline \multicolumn{6}{|l|}{ Self-reported HIV serostatus } \\
\hline Negative & 155 & 79.5 & 433 & 63.1 & $<0.001$ \\
\hline Positive & 40 & 20.5 & 253 & 36.9 & \\
\hline Continuous variables & Median & Range & Median & Range & $k-s$ \\
\hline Age & 35.5 & $17-72$ & 37 & $19-64$ & 0.300 \\
\hline Years of sex with male partners & 19 & $1-55$ & 19 & $2-48$ & 0.164 \\
\hline Number of sexual partners (previous 12 months) & 12 & $1-400$ & 20 & $1-900$ & 0.003 \\
\hline Number of HIV tests (previous 2 years) & 2 & $0-24$ & 2 & $0-30$ & 0.699 \\
\hline
\end{tabular}

As not all questions were answered by all respondents, the total numbers for each variable can be different. 
T A B L E 2

Factors associated with serosorting among HIV-seronegative respondents reporting unprotected anal sex with casual partners during the previous 12 months, France (ANRS-EN17-Presse Gay 2004) - final multivariate model $(\mathrm{n}=576)$

\begin{tabular}{|c|c|c|c|c|c|c|}
\hline & $\mathrm{N}$ & $\%$ & OR & Adjusted OR & $95 \% \mathrm{CI}$ & $\mathrm{p}$ \\
\hline \multicolumn{7}{|c|}{ Looking for sexual partners in cruising venues } \\
\hline No & 103 & 31.4 & 1 & 1 & & \\
\hline Yes & 48 & 19.0 & 0.51 & 0.59 & 0.39 to 0.89 & 0.013 \\
\hline \multicolumn{7}{|c|}{ Looking for sexual partners on websites } \\
\hline No & 70 & 23.9 & 1 & & & \\
\hline Yes & 81 & 28.2 & 1.25 & & & \\
\hline \multicolumn{7}{|c|}{ Drug use (at least one product except cannabis) } \\
\hline No & 117 & 26.9 & 1 & & & \\
\hline Yes & 35 & 23.5 & 0.83 & & & \\
\hline \multicolumn{7}{|c|}{ Number of sexual partners } \\
\hline Over 10 partners & 65 & 21.0 & 1 & 1 & & \\
\hline 1 to 10 partners & 89 & 32.5 & 1.81 & 1.50 & 1.00 to 2.23 & 0.046 \\
\hline \multicolumn{7}{|c|}{ Looking for sexual partners in backrooms } \\
\hline No & 107 & 27,6 & 1 & & & \\
\hline Yes & 44 & 22.9 & 0.78 & & & \\
\hline \multicolumn{7}{|c|}{ Looking for sexual partners in saunas } \\
\hline No & 102 & 29.7 & 1 & & & \\
\hline Yes & 49 & 20.7 & 0.62 & & & \\
\hline \multicolumn{7}{|c|}{ Younger than 30 years } \\
\hline No & 113 & 27.5 & 1 & & & \\
\hline Yes & 39 & 26.2 & 0.94 & & & \\
\hline
\end{tabular}

Hosmer-Lemeshow test: chi-squared $=1.36 ; p=0.506$

T A B L E 3

Factors associated with serosorting among HIV-seropositive respondents reporting unprotected anal sex with casual partners during the previous 12 months, France (ANRS-EN17-Presse Gay 2004) - final multivariate model (n=291)

\begin{tabular}{|c|c|c|c|c|c|c|}
\hline & n & $\%$ & OR & Adjusted OR & $95 \% \mathrm{CI}$ & p \\
\hline \multicolumn{7}{|c|}{ Looking for sexual partners in cruising venues } \\
\hline No & 30 & 21.1 & 1 & 1 & & \\
\hline Yes & 10 & 6.7 & 0.27 & 0.28 & 0.13 to 0.60 & 0.001 \\
\hline \multicolumn{7}{|c|}{ Looking for sexual partners on websites } \\
\hline No & 10 & 8.3 & 1 & 1 & & \\
\hline Yes & 30 & 17.5 & 2.34 & 2.16 & 1.00 to 4.67 & 0.051 \\
\hline \multicolumn{7}{|c|}{ Drug use (at least one product except cannabis) } \\
\hline No & 28 & 15.7 & 1 & & & \\
\hline Yes & 11 & 9.9 & 0.59 & & & \\
\hline \multicolumn{7}{|c|}{ Number of sexual partners } \\
\hline Over 10 partners & 33 & 14.4 & 1 & & & \\
\hline 1 to 10 partners & 7 & 11.9 & 0.80 & & & \\
\hline \multicolumn{7}{|c|}{ Looking for sexual partners in backrooms } \\
\hline No & 12 & 13.2 & 1 & & & \\
\hline Yes & 28 & 14.0 & 1.07 & & & \\
\hline \multicolumn{7}{|c|}{ Looking for sexual partners in saunas } \\
\hline No & 19 & 14.8 & 1 & & & \\
\hline Yes & 21 & 12.9 & 0.85 & & & \\
\hline \multicolumn{7}{|c|}{ Younger than 30 years } \\
\hline No & 36 & 13.8 & 1 & & & \\
\hline Yes & 0 & 0 & 0 & & & \\
\hline
\end{tabular}


survey in order to follow trends in key sexual behavioural indicators. This survey was not originally designed to study serosorting. Only the most recent survey of 2004 collected data suitable for interpretation regarding serosorting.

\section{Data collection}

HIV serostatus at the time of the questionnaire was self-reported by those respondents who stated that they had had at least one HIV test during their lifetime. Respondents were asked if they had UAI with casual partner(s) during the last 12 months. When this was the case, the HIV serostatus of their casual partner(s) was then investigated using the three following questions: "If you had unprotected anal sex with one or more casual partner(s): were there any whom you knew to be seronegative (yes/no)? Were there any you knew to be seropositive (with or without AIDS) (yes/no)? Where there any whose HIV serostatus you did not know (yes/ no)?" The answers were then combined in order to deduce whether respondents practiced serosorting with casual partners or not, as the term "serosorting" itself was not used in the questionnaire.

Respondents were considered to have practiced serosorting with casual partners when they stated that they knew their own HIV serostatus (negative or positive) and that, during the previous 12 months, they had had UAI with one or more casual partners exclusively of the same HIV serostatus as themselves. Respondents who knew their HIV-serostatus and who had had UAI with a casual partner of different or unknown HIV serostatus at least once in the previous 12 months were considered not to practice serosorting. We used these restrictive criteria for serosorting because in the questionnaire no information was collected on the notion of intention or on the HIV serostatus of casual partners with whom condoms were used.

Information on where respondents met their casual partners, such as bars, venues with anonymous sex (saunas, backrooms, cruising venues) or Internet, was collected through a multiplechoice question "Where did you meet your male partners in the previous 12 months?". Drug use was investigated through questions on the consumption of poppers, ecstasy, cocaine, heroin, amphetamines, and hallucinogens during the previous 12 months. All answers were combined in order to have information on the use or not of at least one of these substances.

\section{Participants}

Among the 6,184 MSM who completed the questionnaire during the 2004 survey, self-reported HIV prevalence was 13\% $(n=657)$. The serosorting analysis was restricted to respondents who reported their HIV serostatus (positive, with or without AIDS, or negative), and who reported having UAI with a casual partner at least once during the previous 12 months. The algorithm used to detect serosorting is shown in the Figure.

Accordingly, 1,884 (27\%) respondents were excluded, because they did not know or report their HIV serostatus. Subsequently, those who reported no casual partner $(n=1,290)$, no anal sex with casual partners $(n=341)$ and no unprotected anal sex with casual partners $(n=1,788)$ were also excluded. In the end we analysed data from a sample of 881 respondents.

\section{Statistical analysis}

Descriptive statistics were used to compare the sociodemographic characteristics and sexual behaviour of men who did and did not practise serosorting. Univariate analysis was used to identify factors associated with serosorting and to select variables for inclusion in multivariate analysis (Pearson's test or the non parametric chisquared test). The threshold for statistical significance was set at 0.10 . To identify factors independently associated with serosorting according to HIV status, two stepwise descending multivariate regression analyses were used, eliminating variables with no significant effect at the $5 \%$ level.

The Wald test was used for categorical variables. The HosmerLemeshow test was used to assess the goodness-of-fit of the resulting models. All analyses were carried out with STATATM software version 8.

\section{Results}

The final analysis focused on 881 respondents who stated their HIV serostatus and reported having had UAI with a casual partner at least once during the previous 12 months. The average age of these respondents was 37.3 years. The educational level was high: $61 \%$ of the sample had attended university. The majority (63\%) lived in urban areas of more than 100,000 inhabitants. HIV-positive status was self-reported by $33 \%$ of respondents. Half of respondents used traditional gay meeting places such as bars, saunas, backrooms, cruising venues; the same proportion looked for sexual partners through websites. The use of psychoactive substances was frequent (30\%). The median number of sexual partners in the previous 12 months was significant: 20 (range: 1-400). Of these respondents, 195 (22\%) practiced serosorting when engaging in UAI with casual partners, while the remaining 686 respondents (78\%) did not.

\section{Univariate analysis}

The respondents who did and did not practice serosorting with casual partners were not significantly different with respect to age (35 and 37 years), educational level, or area of residence (Table 1). Men in both groups had an equally marked gay community lifestyle with strong self-definition of their homosexual identity and a long history of sex with men (19 years in both groups). The frequency of HIV serotesting did not differ between the groups, including the HIV-seronegative subpopulation (median 2 tests). A history of at least one STI in the previous 12 months was similarly frequent in both groups.

In contrast, the two groups differed significantly in terms of their HIV serostatus distribution, the number of male partners during the previous 12 months, the use of anonymous gay venues to meet sexual partners, and drug use. Among HIV-seropositive respondents, $14 \%$ practiced serosorting whereas among HIV-seronegative men this proportion was $26 \%$. Respondents who practiced serosorting had fewer male sexual partners during the previous 12 months than respondents who did not practice serosorting (median 12 vs 20 partners) and were less likely to meet sexual partners in venues where sex is generally anonymous (backrooms, saunas and cruising venues). Respondents who practiced serosorting were slightly more likely than other respondents to use the Internet to meet sexual partners. Recreational use of psychoactive substances was less frequent among respondents who practiced serosorting than among other respondents (respectively $24 \%$ and $31 \%$ ).

\section{Multivariate analysis}

In the multivariate analysis on HIV-negative respondents, 2.0\% of the data were missing. In the final multivariate model (Table 2), serosorting of casual partners during the previous 12 months was associated with the use of cruising venues and the number of partners. For HIV-negative men, having 10 or less sexual partners was positively associated with serosorting (AOR 1.50), whereas the use of cruising venues was negatively associated with serosorting 
(AOR 0.59). No other variables were independently associated with serosorting. The final model had a good fit (Hosmer and Lemeshow test, $p>0.05$ ).

In the multivariate analysis on HIV-positive respondents, less than $1 \%$ of the data was missing. In this final multivariate model (Table 3), serosorting of casual partners during the previous 12 months was associated with the use of cruising venues and Internet dating. For HIV-positive men, Internet dating was positively associated with serosorting (AOR 2.16), whereas the use of cruising venues was negatively associated with serosorting (AOR 0.28). No other variables were independently associated with serosorting. The final model had a good fit (Hosmer and Lemeshow test, $\mathrm{p}>0.05$ ).

\section{Discussion}

This study represents the first attempt to explore the practice of serosorting with casual partners by MSM in France, as data from previous surveys were not suitable for this investigation. Among the respondents who stated they had had UAI with a casual partner on at least one occasion during the previous 12 months, 22\% $(n=195)$ were considered to have engaged in serosorting with casual partners.

In our study, the characteristics of MSM who practiced serosorting with casual partners were very similar to those of MSM who did not, although serosorters represented $26 \%$ of HIV-seronegative MSM and $14 \%$ of HIV-seropositive MSM. The multivariate analyses identified variables independently associated with serosorting: HIVseronegative MSM were far more likely to serosort when they had less partners, and HIV-seropositive MSM practiced serosorting more frequently when they used Internet dating, whereas MSM who attended cruising venues were less likely than other MSM to serosort regardless of their HIV-status.

Our findings are similar to those found in other studies carried out in industrialised countries, where HIV-seropositive MSM who serosort are more likely to look for sexual partners on websites $[14,16,18]$. However, our study did not find that HIV-seropositive MSM were more likely than HIV-seronegative MSM to serosort $[10,13,16]$.

This cross-sectional survey was based on a convenience sample, a method widely used for surveys related to MSM [23]. This is mainly due to the difficulties of recruiting a sufficiently large sample of MSM through representative general-population-based surveys. It has been suggested that respondents recruited through the press have a more established sexual identity and sex life, and tend to be exclusively homosexual. They also tend to have confident attitudes and an interest in questions relating to HIV prevention, at least enough to answer a long questionnaire on sexual risk behaviours [24]. This selection bias probably results in an underestimation of sexual risk behaviours among MSM. A social desirability bias may compound this problem, although it should be limited by the use of a self-administered questionnaire.

In this study, the serosorting indicator was constructed retrospectively, based on answers to three questions relating to the HIV serostatus of casual partners with whom respondents had UAI. Only respondents who indicated that they had had UAI with casual partners whose HIV serostatus was identical to theirs were considered to have practiced serosorting. In other words, MSM who reported having also had partners of unknown or discordant HIV serostatus were classified as not using serosorting.
The definition of serosorting used in this study is restrictive, mainly because of the constraints imposed by initial material collected through the questionnaire. No information was collected concerning casual partners' HIV status when condoms were used. The term "serosorting" was not used in the questionnaire, and respondents were not asked about their intention of choosing casual partners according to their HIV status. Hence it was impossible to assess whether those who were considered to have practiced serosorting did so deliberately or not. Likewise, no data contributed to evaluate whether the knowledge of partners' serostatus was the respondent's assumption or the result of direct discussion between partners. Similarly to some other researchers, the implementation of negotiated safety practices in regular partnerships, especially by HIV-negative men, was not taken into account in our definition of serosorting $[21,22,25]$.

Serosorting is a recent concept, its definition is still being developed and no consensus has been reached in literature so far $[13,15,21]$. This explains why the comparison of our results with those of other studies is difficult. Taking into account all the limitations due to the nature of our data, our outcome may be considered an estimation of casual seroconcordance rather than serosorting.

The frequency of serosorting may either be overestimated or underestimated, depending on whether a sub-sample or the total sample is taken into account. Indeed, the rate of serosorting may be expressed as a proportion of UAI respondents with a given HIV serostatus only [25], but it may also be evaluated by a ranking of sexual risks behaviours which is applied to all respondents $[15,17,19,21]$. Nonetheless, in our study, intentional serosorting and seroconcordance by chance could not be distinguished and measured. If the whole sample of respondents had been selected for analysis, it would have meant that the implementation of a risk reduction strategy was intentionally adopted when deciding to have sexual intercourse; this hypothesis being an overstatement.

Our findings show that a large proportion of HIV-seronegative respondents had seroconcordant UAI with casual partners. This is not surprising given that the probability of finding HIVseronegative partners is much higher than the probability of finding HIV-seropositive partners. Nevertheless, our results highlight atrisk behaviours. Indeed, we focused on MSM who practiced UAI with casual partners, and our results may therefore suggest that serosorting was practiced instead of condom use by some HIVseronegative MSM. For HIV-seronegative MSM, the practice of serosorting implies the need for an up-to-date knowledge of their own HIV serostatus obtained through regular screening. However, we found no difference in the frequency of HIV testing in the previous two years between MSM who practiced serosorting and those who did not. Therefore, our findings, consistent with those reported in other research work, suggest that a fraction of MSM who believe themselves to be HIV seronegative could in fact be infected [26]. Recently, Williamson et al. reported that $41 \%$ of men who tested HIV-seropositive were unaware of their status, although less than half of them reported having had a negative test in the previous 12 months [27]. This highlights one major problem related to serosorting, namely the difficulty of being certain of one's own HIV seronegativity. The practice of serosorting by HIV-seronegative individuals as an alternative to condom use for preventing HIV infection has been addressed in previous studies $[11,28]$. In populations with a high incidence of HIV infection, incorrect HIV serostatus assumptions are not that rare, even among individuals 
who have had frequent HIV screening tests during the previous year. Recent studies have raised the possibility that serosorting could in fact increase the risk of HIV transmission $[19,29]$. In contrast, in the specific case of HIV-negative regular partnerships, the negotiated safety has been confirmed to be protective from HIV infection [20].

The rationale of serosorting is also based on the knowledge of a casual partner's serostatus, as stated during preliminary conversation. It requires for users of this strategy to obtain accurate information on the HIV serostatus of each casual partner before engaging in unprotected sex, without assuming serological concordance from the outlook or seroguessing [22]. This issue may be relatively simple to discuss with partners in established relationships, but direct discussion may be more problematic with casual partners encountered in anonymous venues. In fact, we found that participants who attended cruising venues were less likely to serosort, probably because this type of venues tend to encourage immediate anonymous sex, making it more difficult to broach the subject of HIV/AIDS [30].

The use of Internet to meet sexual partners was associated with serosorting for HIV-seropositive respondents, as reported in some studies [15,17,31]. Indeed, it may be easier to disclose one's HIV seropositivity to potential sexual partners during online encounters, especially on "positive-seeking-positive" websites [18]. However, for HIV-seronegative MSM, the HIV-seronegativity of potential sexual partners is as uncertain on the Internet as in other venues. A great deal of sincerity from both partners is required to disclose a person's HIV serostatus, whatever it is.

If the use of psychoactive substances was not independently associated with serosorting, having less partners was predictive of using serosorting among HIV-negative men. Just like in the beginning of the HIV pandemic, MSM who serosorted tended to use other sexual harm-reduction practices [32], which were a smaller number of sexual partners and a lower level of drug use; these are consistent with the time necessary to discuss serostatus and the fact that serosorting requires a high degree of self-control [30].

In our study, serosorting was constructed retrospectively from a behavioural survey. As mentioned, the definition we used did not include notions of intention nor discussions on HIV status, hence limiting interpretations. These new questions will be added to the next EPG survey.

In a context of increasing sexual risk behaviours in France, particularly among HIV-seropositive MSM, the proportion of MSM who practice UAI seroconcordance with casual partners (22\%) can be considered relatively large. On the other hand, 78\% of MSM practiced UAI with casual partners of unknown or discordant HIV serostatus. Moreover, among all respondents of the EPG survey, a large proportion was unaware of their own HIV serostatus (27\%). All these events are consistent with the increase of the number of new HIV diagnoses among MSM in France. HIV prevention campaigns promoting screening and condom use must be pursued. An important limitation of serosorting as a risk reduction strategy is the fact that it exposes both HIV-seronegative and HIVseropositive men to a high risk of STI $[15,33]$. Our results call for the implementation of additional programs to alert HIV-seronegative MSM to the limitations of serosorting casual partners, with respect to the risk of all STI, including HIV/AIDS. HIV-seropositive MSM also need to be more aware that serosorting does not prevent STI transmission.

\section{Acknowledgements}

We would like to thank the gay magazines and websites for their participation in the project; Pascale Bernillon for statistical support; Jean-Claude Desenclos and Stéphane Le Vu for helpful comments.

Funding

The ANRS-EN17-Presse Gay 2004 was funded by ANRS (Agence Nationale sur le Sida et les Hépatites Virales). We thank the ANRS Scientific COPIL members : Nathalie Bajos, Michael Bochow, Alice Bouyssou Michel Bozon, Véronique Dorée Patrick Festy: JeanMarie Firdion; Isabelle Gremy; Marie Jauffret Roustide, Nadine Job-Spira, Marie-Ange Schiltz, Thierry Troussier.

\section{References}

1. Velter A, Semaille C, Bouyssou-Michel A. Les hommes ayant des rapports sexuels avec des hommes [Men who have sex with men]. In: Safar-Semaille C, Lot F. Lutte contre le VIH/sida et les infections sexuellement transmissibles en France. 10 ans de surveillance, 1996-2005. [Fighting HIV/AIDS and sexually transmitted infections in France. 10 years of surveillance, 1996-2005] SaintMaurice: Institut de veille sanitaire; 2007. p. 82-94. French.

2. Likatavicius G, Klavs I, Devaux I, Alix J, Nardone A. An increase in newly diagnosed HIV cases reported among men who have sex with men in Europe, 2000-6: implications for a European public health strategy. Sex Transm Infect. 2008;84(6):499-505.

3. Herida M, Michel A, Goulet V, Janier M, Sednaoui P, Dupin N, et al. Epidemiology of sexually transmitted infections in France. Med Mal Infect. 2005;35(5):281-9.

4. Adam P, Hauet E, Caron C. Recrudescence des prises de risque et des MST parmi les gays. Résultats préliminaires de l’Enquête Presse Gay 2000. [Increase of sexual risk behaviour and sexually transmitted diseases among gay men. Preliminary results of the French Gay Press Survey 2000] Saint-Maurice: Institut de veille sanitaire; 2001. French.

5. Velter A. Rapport Enquête Presse Gay 2004 (ANRS-EN17-Presse Gay 2004) [Report on French Gay Press Survey 2004]. Saint Maurice: Institut de veille sanitaire; 2007. French. Available from: http://www.invs.sante.fr/publications/2007/ epg_2004/epg_2004.pdf

6. Chen SY, Gibson S, Katz MH, Klausner JD, Dilley JW, Schwarcz SK, et al. Continuing increases in sexual risk behavior and sexually transmitted diseases among men who have sex with men: San Francisco, Calif, 1999-2001, USA. Am J Public Health. 2002;92(9):1387-8.

7. Van de Ven P, Prestage G, Crawford J, Grulich A, Kippax S. Sexual risk behaviour increases and is associated with HIV optimism among HIV-negative and HIVpositive gay men in Sydney over the 4 years period to February 2000. AIDS. 2000;14(18):2951-3.

8. Balthasar H, Jeannin A, Dubois-Arber F. [Surveillance of HIV/AIDS-related behaviors among men who have sex with men - Switzerland, 1992-2004]. Int J Public Health. 2007;52(1):27-38. French.

9. Elford J, Bolding G, Davis M, Sherr L, Hart G. Trends in sexual behaviour among London homosexual men 1998-2003: implications for HIV prevention and sexual health promotion. Sex Transm Infect. 2004:80(6):451-4.

10. Elford J, Bolding G, Sherr L, Hart G. High-risk sexual behaviour among London gay men: no longer increasing. AIDS. 2005;19(18):2171-4.

11. Mao L, Crawford JM, Hospers HJ, Prestage GP, Grulich AE, Kaldor JM, et al. "Serosorting" in casual anal sex of HIV-negative gay men is noteworthy and is increasing in Sydney, Australia. AIDS. 2006;20(8):1204-6.

12. Parsons JT, Schrimshaw EW, Wolitski RJ, Halkitis PN, Purcell DW, Hoff CC, et al. Sexual harm reduction practices of HIV-seropositive gay and bisexual men: serosorting, strategic positioning, and withdrawal before ejaculation. AIDS. 2005;19 Suppl 1:S13-S25.

13. Truong HM, Kellogg T, Klausner JD, Katz MH, Dilley J, Knapper K, et al. Increases in sexually transmitted infections and sexual risk behaviour without a concurrent increase in HIV incidence among men who have sex with men in San Francisco: a suggestion of HIV serosorting? Sex Transm Infect. 2006;82(6):461-6.

14. Bolding G, Davis M, Hart G, Sherr L, Elford J. Gay men who look for sex on the Internet: is there more HIV/STI risk with online partners? AIDS. 2005;19(9):9618.

15. Elford J. Changing patterns of sexual behaviour in the era of highly active antiretroviral therapy. Curr Opin Infect Dis. 2006;19(1):26-32.

16. Hospers $\mathrm{HJ}$, Kok G, Harterink P, de Zwart 0 . A new meeting place: chatting on the Internet, e-dating and sexual risk behaviour among Dutch men who have sex with men. AIDS. 2005;19(10):1097-101.

17. Osmond DH, Pollack LM, Paul JP, Catania JA. Changes in prevalence of HIV infection and sexual risk behavior in men who have sex with men in San Francisco: 1997 2002. Am J Public Health. 2007;97(9):1677-83. 
18. Berry M, Raymond HF, Kellogg T, McFarland W. The Internet, HIV serosorting and transmission risk among men who have sex with men, San Francisco. AIDS. 2008;22(6):787-9.

19. Golden MR, Stekler J, Hughes JP, Wood RW. HIV serosorting in men who have sex with men: is it safe? J Acquir Immune Defic Syndr. 2008.

20. Jin F, Crawford J, Prestage GP, Zablotska I, Imrie J, Kippax SC, et al. Unprotected anal intercourse, risk reduction behaviours, and subsequent HIV infection in a cohort of homosexual men. AIDS. 2009;23(2):243-52.

21. Snowden J, Raymond HF, McFarland W. Prevalence of seroadaptive behaviors of men who have sex with men, San Francisco, 2004. Sex Transm Infect. 2009;85(6):469-76.

22. Zablotska IB, Imrie J, Prestage G, Crawford J, Rawstorne P, Grulich A, et al. Gay men's current practice of HIV seroconcordant unprotected anal intercourse: serosorting or seroguessing? AIDS Care. 2009;21(4):501-10.

23. Bochow M, Chiarotti F, Davies P, Dubois-Arber F, Dur W, Fouchard J, et al. Sexual behaviour of gay and bisexual men in eight European countries. AIDS Care. 1994;6(5):533-49.

24. Sandfort TGM. Sampling male homosexuality. In: Bancrofs J. Ed. Researching sexual behavior: methodological issues. Bloomington: Indiana University Press; 1997. p. 261-75.

25. Elford J, Bolding G, Sherr L, Hart G. No evidence of an increase in serosorting with casual partners among HIV-negative gay men in London, 1998-2005. AIDS 2007;21(2):243-5.

26. Centers for Disease Control and Prevention. HIV prevalence, unrecognized infection, and HIV testing among men who have sex with men - five U.S. cities, June 2004-April 2005. MMWR Morb Mortal Wkly Rep. 2005;54(24):597-601.

27. Williamson LM, Dodds JP, Mercey DE, Hart GJ, Johnson AM. Sexual risk behaviour and knowledge of HIV status among community samples of gay men in the UK. AIDS. 2008;22(9):1063-70.

28. Eaton LA, Kalichman SC, Cain DN, Cherry C, Stearns HL, Amaral CM, et al. Serosorting Sexual Partners and Risk for HIV Among Men Who Have Sex with Men. Am J Prev Med. 2007;33(6):479-85.

29. Butler DM, Smith DM. Serosorting can potentially increase HIV transmissions. AIDS. 2007;21(9):1218-20.

30. Rietmeijer CA, Lloyd LV, McLean C. Discussing HIV serostatus with prospective sex partners: a potential HIV prevention strategy among high-risk men who have sex with men. Sex Transm Dis. 2007;34(4):215-9.

31. Chiasson MA, Parsons JT, Tesoriero JM, Carballo-Dieguez A, Hirshfield S, Remien RH. HIV behavioral research online. J Urban Health. 2006;83(1):73-85.

32. Bochow M, Jauffret-Roustide $M$, Michel $A$, Schiltz MA. Les évolutions des comportements sexuels et les modes de vie à travers les enquêtes réalisées dans la presse gay en France (1985-2000) [The evolution of sexual behaviour and lifestyle seen through the surveys conducted by the gay press in France (1985-2000)]. In: Broqua C, Lert F, Souteyrand Y. Homosexualités au temps du sida. Tensions sociales et identitaires. [Homosexuality in times of AIDS. Social and identity tensions].Paris: ANRS; 2003. p. 35-54. French.

33. Dougan S, Evans BG, Elford J. Sexually transmitted infections in Western Europe among HIV-positive men who have sex with men. Sex Transm Dis. 2007;34(10):783-90. 